\title{
The p38 MAPK Pathway in Rheumatoid Arthritis: A Sideways Look
}

\author{
Andrew R. Clark* and Jonathan L.E. Dean \\ Kennedy Institute of Rheumatology Division, Imperial College London, 65 Aspenlea Road, Hammersmith, London W6 \\ $8 L H, U K$
}

\begin{abstract}
The p38 mitogen-activated protein kinase (MAPK) signaling pathway has been strongly implicated in many of the processes that underlie the pathology of rheumatoid arthritis (RA). For many years it has been considered a promising target for development of new anti-inflammatory drugs with which to treat RA and other chronic immune-mediated inflammatory diseases. However, several recent clinical trials have concluded in a disappointing manner. Why is this so, if p38 MAPK clearly contributes to the excessive production of inflammatory mediators, the destruction of bone and cartilage? We argue that, to explain the apparent failure of p38 inhibitors in the rheumatology clinic, we need to understand better the complexities of the p38 pathway and its many levels of communication with other cellular signaling pathways. In this review we look at the p38 MAPK pathway from a slightly different perspective, emphasising its role in post-transcriptional rather than transcriptional control of gene expression, and its contribution to the off-phase rather than the on-phase of the inflammatory response.
\end{abstract}

Keywords: p38 MAPK, inflammatory mediators, gene expression, phosphorylation, listeria monocytogenes.

\section{ACTIVATION OF P38 MAPK}

In mammals four members of the p38 MAPK family are encoded by discrete genes. MAPKs $\mathrm{p} 38 \alpha$ and $\mathrm{p} 38 \beta$ are more than $70 \%$ identical to one another, widely expressed and have essential functions in the regulation of inflammatory responses (for excellent recent reviews of the p38 pathway see [1-3]. The $\delta$ and $\gamma$ isoforms are more distantly related (60\% identical to $\mathrm{p} 38 \alpha$ ), restricted in expression and are thought to have specialised functions in muscle or nerve cells. However, they may be expressed in the inflamed joint, as discussed below. Here we refer to MAPK p38 $\alpha$ unless otherwise stated. Like the related extracellular signal regulated kinase (ERK) and c-Jun N-terminal kinase (JNK) pathways, the p38 MAPK pathway is constructed around a three-tiered phosphorylation cascade. Activation of each MAPK requires phosphorylation at both threonine and tyrosine residues of a T-X-Y motif within a flexible domain known as the activation loop. This induces a structural alteration that catalytically activates the MAPK and increases its affinity for substates. The $\mathrm{X}$ residue that separates the threonine ( $\mathrm{T}$ ) and tyrosine (Y) phosphoacceptor sites is a defining feature of each MAPK family, and is glycine in the case of all the p38 MAPKs. In most cases MAPK kinase (MKK) 3 or 6 is responsible for the activating phosphorylation of p38 MAPKs. In turn, these MKKs are activated via phosphorylation by MAPK kinase kinases (MAPKKKs or MAP3Ks). Several MAP3Ks are capable of activating the p38 MAPK pathway, but in the context of immune and inflammatory responses the most important appears to be TAK1 (transforming growth factor $\beta$-activated kinase). Protein ubiquitination is now known to

*Address correspondence to this author at the Kennedy Institute of Rheumatology Division, Imperial College London, 65 Aspenlea Road, Hammersmith, London W6 8LH, UK; Tel: +44 208383 4430; Fax +44 208 383 4496; E-mail andy.clark@imperial.ac.uk play a major role in the transmission of activating signals from cell surface receptors to TAK1 [4-8].

Ubiquitin is a highly conserved, abundant peptide of 76 amino acids, which can be covalently linked to proteins, in most cases at lysine residues. Ubiquitin itself contains seven lysines (at positions 6, 11, 27, 29, 33, 48 and 63), and can serve as a substrate for addition of further ubiquitin molecules, allowing the construction of long poly-ubiquitin chains. Chains that are built by sequential linkage of ubiquitin molecules through lysine 48 (K48-linked chains) usually signal for protein degradation by the proteasome. In contrast, K63-linked polyubiquitination is often a means of promoting interactions between proteins and propagating signals. Ubiquitination is carried out by an enzymatic cascade having three components known as E1, E2 and E3. An E1 enzyme activates ubiquitin and transfers it to an E2 (ubiquitin conjugating) enzyme, which then passes it to an E3 enzyme (ubiquitin ligase), which in turn mediates substrate-specific ubiquitination. In mammals there are two or more E1, approximately 50 E2 and approximately 600 E3 enzymes. There are also approximately 100 deubiquitinating enzymes (DUBs), possessing different substrate specificities and mechanisms of regulation [9]. A number of these have the property of inhibiting signaling pathways by reversing the formation of K63-linked polyubiquitin chains.

Initiation of p38 MAPK signaling is largely a matter of recruiting and activating ubiquitin ligases, and different cell surface receptors have evolved slightly different means of accomplishing this. Fig. (1) illustrates some features of cell signaling downstream of the $55 \mathrm{kD}$ TNF receptor (p55 or TNFR1). For greater detail and for discussion of the mechanisms employed by different receptors to initiate $\mathrm{p} 38$ MAPK signaling, the interested reader is directed towards excellent recent reviews [4-8, 10]. The key step is the generation of K63-linked polyubiquitin chains, which serve as scaffolds for the oligomerization of TAK1. Such 
Receptor activation and complex formation

Generation of anchored or unanchored polyubiquitin chains

Oligomerisation and autoactivation of TAK1

Phosphorylation and activation of MKK $3 / 6$

Phosphorylation and activation of p38 MAPK
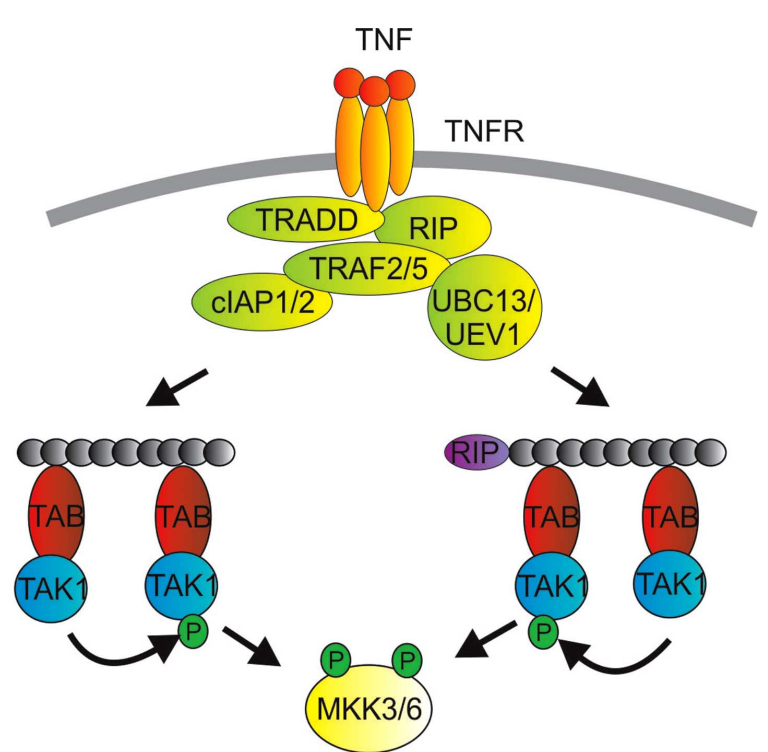

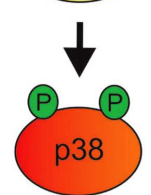

Fig. (1). Activation of p38 MAPK downstrem of TNFR1. Engagement of TNFR1 by trimeric TNF promotes a structural change in the cytoplasmic domain of the receptor (which is itself trimeric). The cytoplasmic death domain of TNFR1 then mediates recruitment of the adaptor protein TRADD (TNF receptor associated death domain protein). This provides a platform for recruitment of additional proteins that include the kinase RIP1 (receptor interacting protein 1), TNF receptor associated factors (TRAFs) 2 and 5, cellular inhibitors of apoptosis proteins (cIAPs) 1 and 2 and, it is thought, the E2 enzymes UBC13 and UEV1. From here, the picture of signaling events becomes a little blurred, because: i) a number of entities in the complex possess ubiquitin E3 ligase activity (namely the TRAFs and the cIAPs); ii) some ubiquitin modifications of proteins in the complex have not been consistently identified in different labs; and iii) downstream events have often been studied in the context of signaling to NF- $\mathrm{KB}$ or JNK rather than p38 MAPK. K63-linked polyubiquitination of the TRAFs themselves or of RIP have been implicated in downstream signaling. A more recent notion is that transmission of the signal depends on the generation of unanchored polyubiquitin chains [166]. TAK1 is next recruited to the complex via interactions between polyubiquitin chains and TAK1 binding proteins (TABs), which possess poly-ubiquitin binding domains [11]. TAK1 proteins that are brought together at polyubiquitin chains then phosphorylate and activate one another. K63-linked ubiquitination of TAK1 itself may also be involved in the activation of p38 MAPK [167].

oligomerization is dependent upon the TAK1 binding proteins (TABs), which possess polyubiquitin binding domains [11]. TAK1 proteins that are brought together at polyubiquitin chains are hypothesized to phosphorylate and activate one another. They are then competent for activation of MKKs 3, 6 and other kinases. An emerging concept is that efficient activation of MAPK cascades may require a proteolytic step to release TAK1 from multiprotein signaling complexes at the cell surface. This was demonstrated for the receptor CD40, a member of the TNF receptor superfamily [12], but may also be true of other receptors that mediate activation of $\mathrm{p} 38$ MAPK. The coupling of MAPK activation and release of TAK1 from the receptor complex is perhaps a mechanism for limiting the duration of the response.

p38 MAPK can also be activated by self phosphorylation at threonine 180 and tyrosine 182. This non-canonical mechanism is conceptually challenging, because it requires a complete change in function from a proline-directed serine or threonine kinase to a dual specificity threonine and tyrosine kinase that has no requirement for an adjacent proline [13]. Autocatalytic activation of p38 MAPK is promoted by its interaction with TAB1, or by the phosphorylation of tyrosine 323 in response to activation of the $\mathrm{T}$ cell receptor [14-16]. It is likely that either TAB1 binding or tyrosine 323 phosphorylation induces a structural alteration that alters the catalytic specificity of p38 MAPK and overcomes steric barriers to self phosphorylation. In principle p38 MAPK may serve different functions when activated non-canonically, because the interaction with TAB 1 or the phosphorylation of tyrosine 323 may also affect its subcellular localisation or ability to recognize substrates [17]. Another important point is that non-canonical activation of $\mathrm{p} 38$ MAPK may not be sensitive to the action of DUBs. However, the role of non-canonical activation of p38 MAPK in arthritis is unclear.

Once activated, either by canonical or non-canonical means, p38 MAPK proceeds to phosphorylate its own substrates in order to bring about changes in expression of pro-inflammatory and other genes. Many of the effects of the p38 MAPK pathway on gene expression are indirect, mediated by phosphorylation and activation of downstream kinases. MAPK-activated kinases MK2 and MK3 are uniquely activated by p38 MAPK, whereas the mitogen- and stress-activated kinases MSK1 and MSK2 can be activated by either p38 MAPK or ERK. Roles of these kinases in the control of inflammatory responses are discussed below. 


\section{REGULATION OF PRO-INFLAMMATORY GENE EXPRESSION BY P38 MAPK}

Several transcription factors can be directly phosphorylated and activated by p38 MAPK to bring about changes in expression of pro-inflammatory and other genes. As reviewed in detail elsewhere, these include activating transcription factor 2 (ATF2, which forms heterodimers with members of the activating protein 1 [AP-1] family), signal transducer and activator of transcription 1 (STAT1, which mediates transcriptional regulation by interferons), members of the ternary complex family, which control expression of c-fos, an AP-1 family member. A necessary note of caution is that sites of phosphorylation may be targeted by kinases other than p38 MAPK, and the physiological relevance of p38-mediated phosphorylation is unclear in some cases.

The link between the p38 MAPK pathway and the function of the transcription factor nuclear factor $\kappa \mathrm{B}(\mathrm{NF}-$ $\kappa \mathrm{B})$ has been controversial for more than a decade. Inhibitors of p38 MAPK did not block the NF- $\kappa B$ signaling pathway but impaired the activation of NF- $\mathrm{BB}-d e p e n d e n t$ genes and reporter constructs. The MSKs, which can be activated by p38 MAPK, offer two potential solutions of this paradox [18, 19]. At least at some NF- $\kappa B$-regulated genes, the phosphorylation of the NF- $\mathrm{BB}$ subunit p65 at serine 276 is required for productive transcription [20-23]. The MSKs are amongst the kinases that can perform this phosphorylation, providing a potential means for the $\mathrm{p} 38$ MAPK pathway to influence transcription of NF- $\mathrm{B}$-dependent genes. The variety of kinases that can phosphorylate p65 S276 means that p38-mediated transcriptional regulation via this mechanism is likely to be highly gene-specific and contextdependent. The p38 MAPK pathway was also found to promote recruitment of NF- $\kappa \mathrm{B}$ to certain pro-inflammatory promoters, which was accompanied by phosphorylation of histone $\mathrm{H} 3$ at serine 10 [24]. The MSKs are amongst several kinases that can phosphorylate H3 S10. In any case, promoter-specific recruitment of MSKs may enhance transcriptional activation by $\mathrm{NF}-\kappa \mathrm{B}$ either by modifying chromatin structure to increase $\mathrm{NF}-\kappa \mathrm{B}$ recruitment, or by post-translational modification of an NF- $\kappa \mathrm{B}$ component. MSK recruitment to pro-inflammatory promoters has been demonstrated $[25,26]$, but it is so far unclear how this recruitment occurs, or what is the causal link between the two MSK-mediated phosphorylations. The MSKs are also known to phosphorylate and activate members of the ATF/CREB (cAMP response element binding protein) family of transcription factors $[18,19]$.

Many reviews of p38 MAPK function emphasize these transcriptional effects, but post-transcriptional effects are at least as important in the regulation of inflammatory responses. Genome-wide analyses reveal that only half of the changes in gene expression during a stereotypical immune response can be accounted for by transcriptional regulation [27-29]. The remainder are dependent on changes in mRNA stability. The modulation of mRNA stability is a powerful mechanism for bringing about rapid changes of gene expression, such as those that occur when the innate immune system first encounters a pathogen $[30,31]$. As we will describe below, defects in post-transcriptional control can contribute to inflammatory pathologies. First, we will give a brief outline of post-transcriptional regulatory mechanisms and how they are influenced by the p38 MAPK pathway.

The information content of an mRNA resides within the open reading frame, whilst the non-coding regions (or

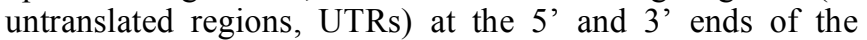
mRNA convey instructions for its localization, translation and degradation (Fig. 2). Determinants of mRNA stability are most often located within the 3' UTR, the best characterized being adenosine/uridine-rich elements (AREs). AREs contain repeats of the sequence AUUUA, and are recognized by mRNA destabilizing proteins including tristetraprolin (TTP) and several others. TTP recruits a large complex of deadenylases and associated proteins to remove the poly(A) tails of mRNAs that it is bound to [32-35]. In most cases the removal of the poly(A) tail is rapidly followed by degradation of the mRNA body.

The earliest experiments with p38 inhibitors implicated a role for the p38 MAPK pathway in the regulation of translation of pro-inflammatory mRNAs, which is still emphasized in many review articles. However, an overwhelming majority of more recent papers instead point to a role for $\mathrm{p} 38$ in the regulation of mRNA stability (see references in [36, 37]). Genetic and biochemical experiments in a number of labs have elucidated how TTP-mediated mRNA turnover is influenced by the p38 MAPK pathway $[38,39]$ (Fig. 2). When activated by p38 MAPK, the downstream kinase MK2 phosphorylates murine TTP at serines 52 and 178 (S60 and S186 of the human protein) [40, 41]. This phosphorylation impairs the ability of TTP to recruit the deadenylase complex, and therefore stabilizes mRNAs that are targeted by TTP [33]. The kinase MK3 is closely related to $\mathrm{MK} 2$ and appears to serve a similar function in mRNA stabilisation, although it may be less strongly expressed than MK2 [38, 42]. Many mRNAs that are relevant to inflammatory arthritis are destabilized by $\mathrm{p} 38$ MAPK inhibitors (for example TNF, Cyclooxygenase-2, IL$1 \beta$, IL-6) [36, 37, 43-47]. In $\mathrm{Ttp}^{-/-}$mouse macrophages several of these pro-inflammatory mRNAs are constitutively stable and insensitive to p38 MAPK inhibition [48]. Therefore the inactivation of TTP is the major mechanism of mRNA stabilization by the p38 MAPK pathway in these cells. Other mechanisms of regulation of mRNA stability by p38 MAPK have also been described, and may be more significant in cell types other than macrophages [30, 37].

The likely relevance of this post-transcriptional mechanism to rheumatoid arthritis has been well illustrated by a number of genetically-modified mouse models. Mice expressing a wild-type human TNF transgene were healthy, whereas those expressing a mutated human TNF transgene with a heterologous, non-ARE 3' UTR developed polyarthritis $[49,50]$. This finding pointed to a role for the 3 ' UTR in restricting TNF expression. A more elegant experiment by the same group involved the germline deletion of the ARE from the mouse TNF locus [51]. The resulting $\triangle \mathrm{ARE}$ mouse again overexpressed TNF and developed erosive arthritis (amongst other inflammatory and autoimmune pathologies). In the $\triangle \mathrm{ARE}$ mouse, TNF expression was insensitive to p38 inhibition. The TTP knockout mouse also has a complex inflammatory syndrome that includes erosive arthritis and features of autoimmunity [52]. This syndrome is largely due to an increase in the 


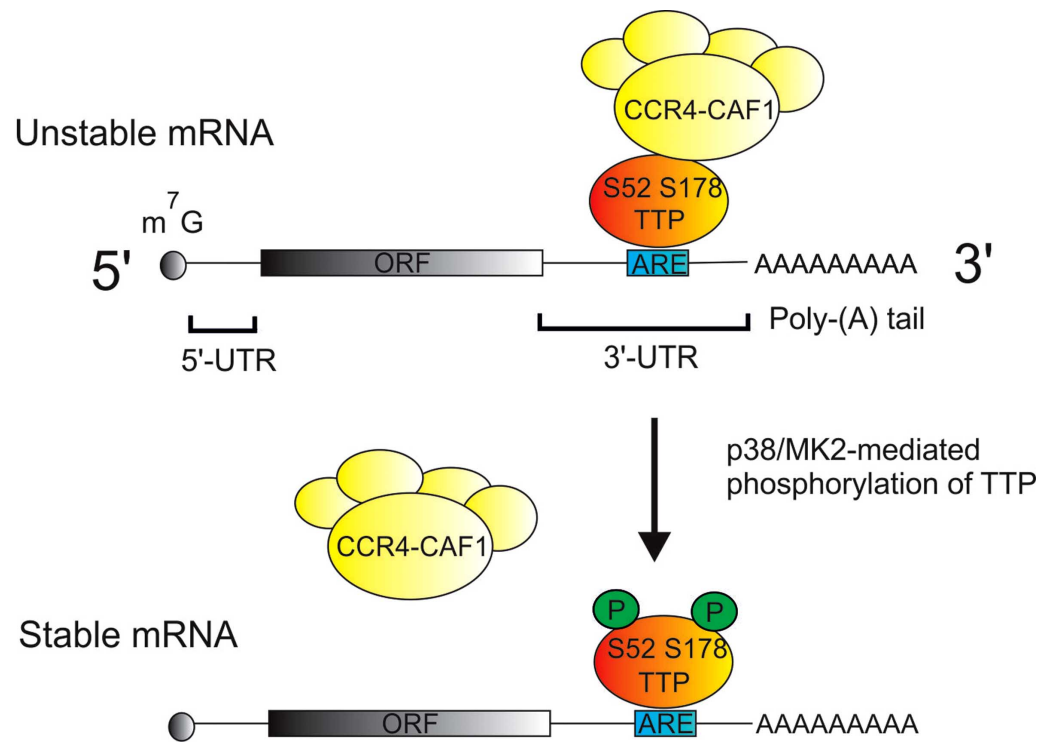

Fig. (2). Regulation of mRNA stability by 338 MAPK and TTP. Most mRNAs are modified by the addition of a 7-methyl guanisine (m7G cap) at the $5^{\prime}$ end, and a poly adenosine or poly(A) tail at the $3^{\prime}$ end. The protein coding open reading frame (ORF) is flanked by $5^{\prime}$ and $3^{\prime}$ untranslated regions (UTRs). Adenosine/uridine rich elements (AREs) in the 3' UTRs of many cytokine mRNAs are specifically recognized by tristetraprolin (TTP), which then recruits the CCR4/NOT deadenylase complex. This complex catalyzes the removal of the poly(A) tail and initiates the degradation of the mRNA body. Following its activation by p38 MAPK, MAPK-activated protein kinase 2 (MK2) phosphorylates serines 52 and 178 of TTP, preventing the recruitment of the deadenylase complex and thus stabilizing mRNAs that are recognized by TTP.

stability of TNF mRNA and the expression of TNF protein in macrophages $[53,54]$. Other pro-inflammatory genes are also disregulated in the absence of TTP protein, and may contribute to the phenotype [55].

\section{INACTIVATION OF P38 MAPK}

The timely inactivation of the p38 MAPK pathway is necessary to prevent excessive inflammatory responses. The most efficient mechanism of p38 MAPK inactivation is dephosphorylation, in particular by dual specificity phosphatases (DUSPs) that catalyze removal of both threonine and tyrosine phosphates [56, 57]. The DUSP family contains approximately ten members, several of which are able to dephosphorylate and inactivate p38 MAPK, at least in vitro or under conditions of overexpression. DUSP1 appears to have a particularly important role as a regulator of inflammatory responses [5860]. Mouse Dusp $1^{-/-}$macrophages display exaggerated or prolonged activation of $\mathrm{p} 38$ MAPK and JNK in response to pro-inflammatory stimuli, and overexpress a variety of proinflammatory factors. Dusp 1 knockout mice are healthy and fertile under sterile conditions, but catastrophically overrespond to pro-inflammatory insults, for example injection of endotoxin, induction of an allergic response or infection with gram negative or positive bacteria. Most relevant to this discussion, they develop a more aggressive form of collageninduced arthritis than wild type control mice [61] (our unpublished observations).

Mathematical models suggest that modulating the activity or expression of phosphatases is a powerful means of controlling the strength and duration of activation of MAPK pathways, and hence the cellular response in terms of gene expression [62]. Consistent with its role as a central regulator of inflammation, DUSP1 expression is influenced by a wide variety of pro- and anti-inflammatory factors [58-
60]. In the majority of resting cells DUSP1 is very weakly expressed, but is strongly and transiently upregulated by many pro-inflammatory agonists, its expression temporally coinciding with the off-phase of p38 activity. IL-10 may enhance or prolong DUSP1 expression in order to impair p38 MAPK signaling [63], whilst interferon $\gamma$ may inhibit DUSP1 expression to enhance p38 MAPK signaling [64].

For approximately sixty years, glucocorticoids (GCs) have been used to treat rheumatoid arthritis and other chronic immune-mediated inflammatory diseases [65-67]. They possess genuine disease-modifying activity, but their use is limited by unpredictable and sometimes severe side effects $[68,69]$. The upregulation of DUSP1 and the consequent inhibition of p38 MAPK is emerging as one mechanism that underlies anti-inflammatory effects [70-72]. GCs have been shown to impair p38 MAPK function in many cell types, but in Dusp1 $1^{-/}$macrophages they neither inhibit p38 MAPK nor strongly inhibit expression of several pro-inflammatory mediators, including TNF [73]. In experimental models of sepsis or localized acute inflammation, therapeutic effects of GCs were dependent on DUSP1 [73, 74]. Our preliminary data suggest that anti-inflammatory effects of GCs are also mediated by DUSP1 in collagen-induced arthritis. The interesting question is whether GCs depend upon this antiinflammatory mechanism in man. Small clinical studies have suggested that the GC-induced upregulation of DUSP1 and inhibition of p38 MAPK are both impaired in severe and/or GC resistant asthma [75-78]. No equivalent study has been published in rheumatoid arthritis.

Macrophage migration inhibitory factor (MIF) is a cytokine thought to contribute to several inflammatory pathologies [79-81]. It is upregulated by GCs but antagonizes their anti-inflammatory effects, leading to the suggestion that MIF neutralization might enhance GC 
efficacy. Pro-inflammatory effects of MIF are thought to be mediated by inhibition of expression of DUSP1 and consequent enhancement of p38 MAPK signaling [82-85].

\section{THE P38 MAPK PATHWAY IN NEGATIVE FEEDBACK CONTROL OF INFLAMMATION}

The innate immune system is characterized by exquisite sensitivity to markers of infection or tissue injury, very rapid production of powerful pleiotropic inflammatory mediators such as TNF, and a capacity for self amplification. These features create a danger of runaway inflammatory responses. Unprovoked, excessive or unduly prolonged expression of pro-inflammatory genes is normally prevented by multiple layers of negative feedback regulation. The p38 MAPK pathway is central to many of these feedback loops.

The p38 MAPK pathway regulates expression of DUSP1 via MSK-mediated phosphorylation of CREB/ATF transcription factors, which recognize highly conserved sites in the DUSP1 promoter [86-90]. The stability of DUSP1 mRNA has also been shown to be regulated by p38 MAPK [91] which is consistent with the identification of DUSP1 as a target of TTP [92-94]. Other studies implicate posttranslational control of DUSP1 protein stability or catalytic activity by the p38 pathway [95, 96]. Whether transcriptional, post-transcriptional or post-translational mechanisms are involved, the control of DUSP1 function by p38 MAPK is an excellent example of negative feedback. But DUSP1 also regulates the activity of JNK and (under some circumstances) ERK. Therefore inhibition of $\mathrm{p} 38$ MAPK and blockade of DUSP1 expression or function might have unanticipated consequences, such as enhanced or prolonged activation of other signaling pathways.

The expression of TTP is controlled by the p38 MAPK pathway at several levels. Transcription is regulated by the MSKs [97], and stability of TTP mRNA is regulated by MK2 $[98,99]$. The phosphorylation of TTP protein by MK2 causes its stabilization by preventing proteasome-mediated degradation [97, 98] (Fig. 3). The phosphate groups at serines 52 and 178 can be removed by protein phosphatase 2A (PP2A) [100], therefore the level of expression of TTP protein is tightly regulated by a dynamic equilibrium

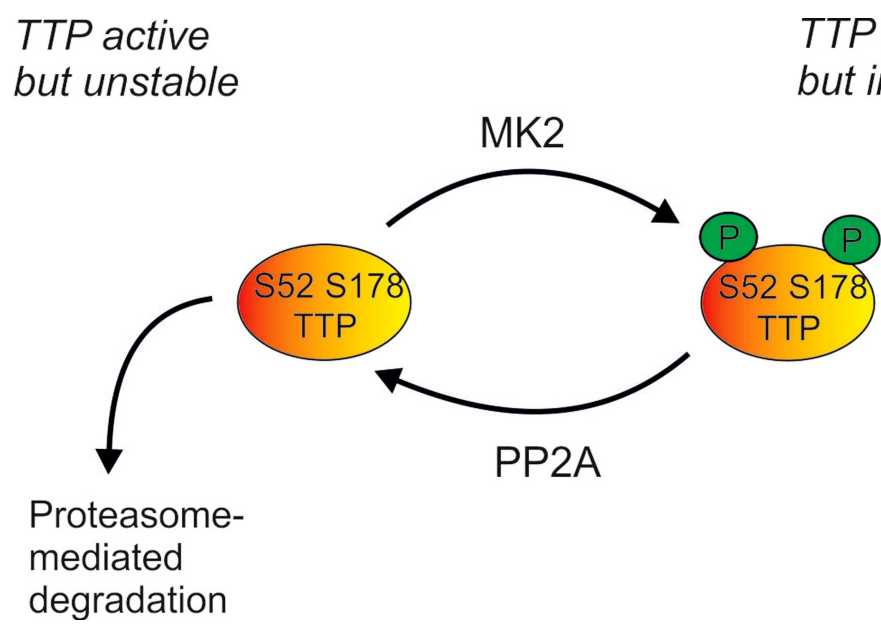

Fig. (3). Regulation of cellular levels of TTP protein by the p38 MAPK pathway. Phosphorylation of TTP by MK2 renders it inactive (as described in Fig 2), but also protects it against proteasome-mediated degradation. TTP can be dephosphorylated by protein phosphatase 2A (PP2A), and perhaps by other phosphatases. Cellular levels of TTP are therefore dependent on a dynamic equilibrium of protein synthesis, proteasome-mediated degradation, MK2-mediated phosphorylation and PP2A-mediated dephosphorylation. between MK2-mediated phosphorylation and PP2Amediated dephosphorylation. At first sight it seems paradoxical that the p38 MAPK pathway promotes both the accumulation and the inactivation of TTP. This has been interpreted as a means of coupling the stability of proinflammatory mRNAs to the activation state of the p38 pathway. In the early phase of an inflammatory response, TTP is inactivated as it accumulates, allowing proinflammatory transcripts to remain stable for long enough to be translated. As cellular p38 activity declines, the equilibrium shifts in favour of TTP dephosphorylation and activation, so that the existing pro-inflammatory mRNAs can be rapidly degraded. A consequence of this intricate coupling is that, in vitro at least, long-term inhibition of $\mathrm{p} 38$ MAPK prevents the accumulation of TTP and renders target transcripts constitutively stable [48].

The cytokine IL-10 has complex, broadly antiinflammatory effects on a wide variety of cells including macrophages [101-103]. In macrophages the expression of IL-10 is upregulated by pro-inflammatory stimuli, usually in a rather delayed manner. This can be seen as a homeostatic mechanism to guard against excessive inflammation. For example, experimental arthritis in the mouse can be treated using recombinant IL-10 [104], and is exacerbated in mice lacking IL-10 [105]. The interesting point here is that IL-10 expression is strongly regulated by p38 MAPK at both transcriptional and post-transcriptional levels. Transcription is upregulated by MSKs via phosphorylation of CREB/ATF proteins [87, 90]. p38-mediated phosphorylation of Sp1 has also been implicated in the control of expression [106, 107]. IL-10 mRNA is also recognized by TTP, and dramatically destabilized by inhibition of p38 MAPK [48, 108]. This nicely illustrates a general point about negative feedback effectors. Their expression is commonly controlled by the same signaling pathways that regulate expression of proinflammatory genes. Such sharing of control mechanisms will normally safeguard against unrestrained production of inflammatory mediators.

Another mechanism of negative feedback involves the p38-mediated phosphorylation of one or more of the TAK1binding proteins, causing inhibition of TAK1 catalytic TTP stable
but inactive 
activity [109-112]. Inhibitors of p38 MAPK are thought to increase the activation of $\mathrm{JNK}$ and $\mathrm{NF}-\mathrm{\kappa B}$ by interfering with this negative feedback mechanism and thereby enhancing or prolonging TAK1 activation. MAPK p38 has also been reported to inhibit JNK signaling via effects on the upstream activator mixed lineage kinase 3 (MLK3) [113]. In addition, p38 MAPK may negatively regulate responses to IL-6 by increasing the expression of SOCS-3 (suppressor of cytokine signaling 3) [114-116]. There are likely to be several additional mechanisms of negative feedback regulation of the p38 MAPK pathway, or negative crosstalk between p38 MAPK and other pro-inflammatory signaling pathways.

\section{THE P38 MAPK PATHWAY IN RHEUMATOID ARTHRITIS}

The first generation of p38 MAPK inhibitors were discovered as compounds that decreased the expression of pro-inflammatory cytokines in myeloid cells [117]. Successive generations of increasingly potent and specific inhibitors have been invaluable tools for research into the biological roles of $\mathrm{p} 38 \alpha$ and $\beta$ (whilst leaving the functions of p38 $\gamma$ and $\delta$ more obscure). Information from many of these studies has added weight to the argument that chronic inflammatory diseases might be treated by targeting p38 MAPK [118-121].

Of the p38 MAPK family members it is almost certainly p $38 \alpha$ that contributes most to the pathology of inflammatory arthritides. Experimental arthritis is unaltered in mice lacking p38 $\beta$ [122], whereas deletion in adult mice of the Mapk14 gene that encodes $\mathrm{p} 38 \alpha$ protects them against TNFinduced inflammatory bone loss [123]. MK2 likely plays a critical role downstream of $\mathrm{p} 38 \alpha$, because the MK2 knockout mouse is protected against experimental arthritis [124]. Disruption of the genes encoding either MKK3 or MKK6 also protects against experimental arthritis [125, 126]. Upstream of this level there is not yet any definitive information. TAK 1 protein and mRNA are expressed in RA synovial fibroblasts [127], but the mouse knockout is embryonic lethal. Perhaps conditional knockouts of the Map3k7 gene (which encodes TAK1) will reveal whether this kinase has an essential role in inflammatory arthritis, as suspected.

In the inflamed joints of patients with rheumatoid arthritis and in animal models of the disease, activation of p38 MAPK and the upstream kinases MKK3 and MKK6 is detected in macrophages and fibroblasts of the synovial lining layer, and at sites of bone erosion [128-134]. Activation of the $\mathrm{p} 38 \alpha$ isoform appears to predominate, but there is also evidence of phosphorylated p38 $\beta$ and $\gamma$ in certain cells [129]. Pro-inflammatory cytokines such as TNF and IL-1 in the inflamed joint presumably contribute to p38 MAPK activation. There may also be activation of the pathway by ligands generated locally through cell damage or proteolysis of the extracellular matrix.

As outlined above, p38 MAPK is believed to contribute to the overexpression of pro-inflammatory cytokines, chemokines, matrix metallo-proteinases and signaling enzymes such as COX-2 in the inflamed synovium. Phosphorylated p38 is also detected in the vascular endothelial cells of the blood vessels infiltrating the synovium, where it regulates expression of genes encoding cell adhesion molecules. Receptor Activator of NF- $\mathrm{BB}$ (RANK) plays a critical role in the differentiation and activation of osteoclasts, and therefore in the inflammatory osteolysis that accompanies RA $[135,136]$. Engagement of RANK by its ligand RANKL activates p38, which in turn increases the expression and/or activity of transcription factors including NFAT2 (nuclear factor of activated T cells 2), MITF (microphthalmia-associated transcription factor) and PU.1 (purine-rich element binding factor 1) [137-144]. These transcription factors promote expression of cathepsin $\mathrm{K}$, tartrate-resistant acid phosphatase and other genes essential to the resorptive function of osteoclasts. In chondrocytes the p38 MAPK pathway has been implicated in the expression of matrix metalloproteinase 13 (collagenase 3 ), which contributes to the degradation of cartilage [145148]. Hence the fingerprints of p38 are clearly seen on several of the features of RA; abundant expression of proinflammatory cytokines and chemokines, increased vascularization and recruitment of lymphocytes, proteolytic degradation of bone and cartilage.

\section{THERAPEUTIC TARGETING OF THE P38 MAPK PATHWAY IN RA}

In a potentially crowded market, some investigators and pharmaceutical companies have chosen to focus on targets within the p38 pathway, other than p38 MAPK itself. For example, it has been argued that blocking the pathway at a higher level is likely to exert broader anti-inflammatory effects and reduce the risk of signal diversion into other proinflammatory pathways [149]. From this perspective TAK1 is an interesting candidate, since it appears to be involved in signaling downstream of several important receptors $[120$, 150-152]. However, involvement of TAK1 in the differentiation of regulatory $\mathrm{T}$ cells suggests that prolonged TAK1 inhibition might risk inducing or exacerbating autoimmune disease [153]. Another possibility is that therapeutic targets may be found amongst K63 ubiquitin ligases that assist in the initiation of p38 MAPK signaling [154]. At present, inhibitors of E3 ubiquitin ligases, TAK1, other MAP3Ks or even MAP2Ks are some distance from the clinic. A knockout mouse lacking the downstream kinase MK2 is viable and healthy but underexpresses proinflammatory cytokines and is relatively resistant to challenges such as LPS injection or experimental induction of arthritis [124]. This suggests that long term inhibition of MK2 may be a safe and effective means of treating RA and other diseases [151, 155]. A novel MK2 inhibitor was recently reported to inhibit paw swelling in the streptococcal cell wall model of arthritis [156]. However, some notes of caution need to be sounded. In one study the absence of MK2 exacerbated rather than ameliorated TNF-driven inflammatory bowel disease [157]. In a second, MK2 knockout provided no protection in some models of dermal contact hypersensitivity [158]. In another, MK2 mice were found to have increased susceptibility to the intracellular pathogen Listeria monocytogenes [159]. These findings point to certain concerns that might arise from therapeutic targeting of MK2.

In this field, the majority of pharmaceutical companies have invested in the development of specific inhibitors of p38 MAPK itself. Although several clinical trials have been 
completed, relatively little information has entered the public domain [160]. Yet, from available data, certain common themes are evident [149, 161]. In spite of increasing specificity of inhibitors, problems of toxicity in liver, skin and/or central nervous system have not been eliminated altogether. Because the inhibitors that have been tested belong to several distinct chemical classes, these adverse events could be mechanism-related, in other words unavoidable consequences of interrupting necessary physiological functions of p38 MAPK [2]. It is worth noting that observations from knockout mice suggest essential roles of the p38 MAPK pathway in muscle differentiation, erythropoiesis and bone formation [2, 162-164]. These observations raise concerns about p38 inhibition that remain (so far as we are aware) hypothetical.

More interestingly from the perspective of this review, a number of inhibitors displayed transient efficacy (for example as measured by down regulation of $\mathrm{C}$-reactive protein). As one commentator has remarked, "The etiology of this phenomenon remains unknown but must lie in one or more biologic adaptations that allow escape from this pathway... One can't help believing that to best understand the failure of this class of therapies, we need to better understand this biologic adaptation" [161].

It is likely that the failure of p38 inhbitors is connected to the important role of the p38 pathway in the negative feedback control of inflammatory responses. For example, as has been demonstrated in isolated macrophages, chronic inhibition of p38 may prevent expression of TTP, so that any pro-inflammatory mRNAs that are synthesised remain constitutively stable [48]. Because of extensive crosstalk, there is also the possibility that prolonged p38 inhibition may enhance the activity of other signaling pathways such as the JNK or NF- $\kappa \mathrm{B}$ pathways, providing alternative routes to the expression of inflammatory mediators. Crosstalk between the p38 and JNK pathways may also provide an explanation for hepatoxicity in trials of p38 inhibitors. At any rate, enthusiasm for $\mathrm{p} 38$ inhibition now seems to be waning $[118,161]$. For example, at the time of writing the website www.clinicaltrials.gov lists no ongoing trials of p38 inhibitors in RA. It may now prove difficult to identify the reason or reasons behind loss of anti-inflammatory efficacy, which is doubly unfortunate. The negative feedback loops that limit pro-inflammatory signaling pathways may provide a key to understanding not only the disappointing outcomes of p38 inhibitor trials, but also the chronicity of diseases like RA (see schematic figure in [165]).

Under most experimental conditions, negative feedback mechanisms ensure that $\mathrm{p} 38$ activation in response to a proinflammatory agonist is transient. In many cases the response is also followed by a refractory condition, in which the kinase pathway responds weakly to the same agonist or a different pro-inflammatory agonist (tolerance or crosstolerance). Whilst this phenomenon is easy to study in static cell populations in vitro, the situation in vivo is much more complex, with interactions between distinct populations evolving as cells migrate into and out of sites of inflammation, proliferating, differentiating or dying as they do so. Nevertheless, there is a puzzle in the chronic activation of p38 MAPK that is observed in the rheumatoid joint. If negative feedback loops act efficiently to attenuate the response of the p38 pathway in individual cells, how can the pervasive activation of p38 in synovial tissue be explained? It has been suggested that RA depends upon a vicious cycle of inflammation, which provokes tissue damage and catabolism of extracellular matrix, generating ligands that activate Toll-like receptors, inducing inflammation ... and so on. Persistence of inflammatory stimulus can help to explain pervasive p38 activation only if the refractory state is relatively short-lived, or if cell populations are continually replenished and it is the newly arrived cells, encountering the stimulus for the first time, that stain positive for activated p38 MAPK. But more than $75 \%$ of synovial lining cells and vascular endothelial cells in the inflamed synovium stain positively for phosphorylated p38, which is very difficult to explain in terms of activated incomer cells. In particular, vascular endothelial cells and fibroblasts are not thought to turn over rapidly, so the majority of activated cells of these types have likely been resident in the inflammatory milieu for some time. This suggests that negative feedback loops, which normally limit the strength and duration of p38 activation, are ineffective in the rheumatoid joint. In turn this raises new questions and opens new avenues for future research. Is there concrete evidence for failure of specific negative feedback mechanisms in chronically inflamed tissues? How might such apparently robust control systems break down, and could anything be done to prevent or reverse that malfunction, reinforce negative feedback and restore homeostasis? These questions might provide fertile ground for new approaches to the treatment of RA and other chronic immune-mediated inflammatory diseases.

\section{ACKNOWLEDGEMENTS}

Our work is supported by Arthritis Research UK, the Medical Research Council UK and the Kennedy Trust.

\section{CONFLICT OF INTEREST}

The authors confirm that this article content has no conflicts of interest.
ABBREVIATIONS
$\mathrm{ARE}=$ Adenosine/uridine-rich element
ATF2 $=$ Activating transcription factor 2
AP-1 = Activating protein 1
cIAP $=$ Cellular inhibitor of apoptosis
COX-2 = Cyclooxygenase 2
CREB $=$ Cyclic AMP response element binding protein
DUB = Deubiquitinating enzyme
DUSP $=$ Dual specificity phosphatase
ERK $=$ Extracellular signal regulated kinase
$\mathrm{GC}=$ Glucocorticoid
IL $\quad=$ Interleukin
JNK $=$ cJun N-terminal kinase
MAPK = Mitogen-activated protein kinase
MK = MAPK activated protein kinase
MIF = Macrophage migration inhibitory factor 


$$
\begin{aligned}
& \text { MITF = Microphthalmia-associated transcription factor } \\
& \text { MKK = MAPK kinase } \\
& \text { MSK = Mitogen- and stress-activated kinase } \\
& \text { NFAT }=\text { Nuclear factor of activated } \mathrm{T} \text { cells } \\
& \mathrm{NF}-\kappa \mathrm{B}=\text { Nuclear factor of } \kappa \mathrm{B} \\
& \mathrm{PP} 2 \mathrm{~A}=\text { Protein phosphatase } 2 \mathrm{~A} \\
& \text { PU.1 = Purine rich element binding factor } 1 \\
& \text { RA }=\text { Rheumatoid arthritis } \\
& \text { RANK }=\text { Receptor activator of NF- } \kappa B \\
& \text { RANKL = RANK ligand } \\
& \text { RIP = Receptor interacting protein } \\
& \text { SOCS3 = Suppressor of cytokine signaling } 3 \\
& \text { STAT }=\text { Signal transducer and activator of transcription } \\
& \mathrm{TAB}=\mathrm{TAK} 1 \text {-binding protein } \\
& \text { TAK } 1=\text { TGF } \beta \text {-activated kinase } 1 \\
& \text { TGF } \beta=\text { Transforming growth factor } \beta \\
& \mathrm{TNF}=\text { Tumor necrosis factor } \\
& \text { TNFR }=\text { TNF receptor } \\
& \text { TRADD }=\text { TNF receptor-associated death domain protein } \\
& \text { TRAF }=\text { TNF receptor-associated factor } \\
& \text { TTP }=\text { Tristetraprolin } \\
& \text { UTR }=\text { Untranslated region }
\end{aligned}
$$

\section{REFERENCES}

[1] Coulthard LR, White DE, Jones DL, McDermott MF, Burchill SA. p38(MAPK): stress responses from molecular mechanisms to therapeutics. Trends Mol Med 2009; 15: 369-79.

[2] Cuadrado A, Nebreda AR. Mechanisms and functions of p38 MAPK signalling. Biochem J 2010; 429: 403-17.

[3] Gaestel M, Kotlyarov A, Kracht M. Targeting innate immunity protein kinase signalling in inflammation. Nat Rev Drug Discov 2009; 8: 480-99.

[4] Adhikari A, Xu M, Chen ZJ. Ubiquitin-mediated activation of TAK1 and IKK. Oncogene 2007; 26: 3214-26.

[5] Bhoj VG, Chen ZJ. Ubiquitylation in innate and adaptive immunity. Nature 2009; 458: 430-7.

[6] Bianchi K, Meier P. A tangled web of ubiquitin chains: breaking news in TNF-R1 signaling. Mol Cell 2009; 36: 736-42.

[7] Karin M, Gallagher E. TNFR signaling: ubiquitin-conjugated TRAFfic signals control stop-and-go for MAPK signaling complexes. Immunol Rev 2009; 228: 225-40.

[8] Wertz IE, Dixit VM. Regulation of death receptor signaling by the ubiquitin system. Cell Death Differ 2010; 17: 14-24.

[9] Reyes-Turcu FE, Ventii KH, Wilkinson KD. Regulation and cellular roles of ubiquitin-specific deubiquitinating enzymes. Annu Rev Biochem 2009; 78: 363-97.

[10] O'Neill LA. The interleukin-1 receptor/Toll-like receptor superfamily: 10 years of progress. Immunol Rev 2008; 226: 10-8.

[11] Prickett TD, Ninomiya-Tsuji J, Broglie P, et al. TAB4 stimulates TAK1-TAB1 phosphorylation and binds polyubiquitin to direct signaling to NF-kappaB. J Biol Chem 2008; 283: 19245-54.

[12] Matsuzawa A, Tseng PH, Vallabhapurapu S, et al. Essential cytoplasmic translocation of a cytokine receptor-assembled signaling complex. Science 2008; 321: 663-8.

[13] Lochhead PA. Protein kinase activation loop autophosphorylation in cis: overcoming a Catch-22 situation. Sci Signal 2009; 2: pe4.

[14] Ashwell JD. The many paths to $\mathrm{p} 38$ mitogen-activated protein kinase activation in the immune system. Nat Rev Immunol 2006; 6: 532-40.
[15] Ge B, Gram H, Di Padova F, et al. MAPKK-independent activation of p38alpha mediated by TAB1-dependent autophosphorylation of p38alpha. Science 2002; 295: 1291-4.

[16] Jirmanova L, Sarma DN, Jankovic D, Mittelstadt PR, Ashwell JD. Genetic disruption of p38alpha Tyr323 phosphorylation prevents Tcell receptor-mediated $\mathrm{p} 38$ alpha activation and impairs interferongamma production. Blood 2009; 113: 2229-37.

[17] Lu G, Kang YJ, Han J, Herschman HR, Stefani E, Wang Y. TAB-1 modulates intracellular localization of p38 MAP kinase and downstream signaling. J Biol Chem 2006; 281: 6087-95.

[18] Arthur JS. MSK activation and physiological roles. Front Biosci 2008; 13: 5866-79.

[19] Vermeulen L, Berghe WV, Beck IM, De Bosscher K, Haegeman G. The versatile role of MSKs in transcriptional regulation. Trends Biochem Sci 2009; 34: 311-8.

[20] Chen LF, Williams SA, Mu Y, et al. NF-kappaB RelA phosphorylation regulates RelA acetylation. Mol Cell Biol 2005; 25: 7966-75.

[21] Okazaki T, Sakon S, Sasazuki T, et al. Phosphorylation of serine 276 is essential for p65 NF-kappaB subunit-dependent cellular responses. Biochem Biophys Res Commun 2003; 300: 807-12.

[22] Nowak DE, Tian B, Jamaluddin M, et al. RelA Ser276 phosphorylation is required for activation of a subset of NF-kappaBdependent genes by recruiting cyclin-dependent kinase 9/cyclin T1 complexes. Mol Cell Biol 2008; 28: 3623-38.

[23] Olson CM, Hedrick MN, Izadi H, Bates TC, Olivera ER, Anguita J. p38 mitogen-activated protein kinase controls NF-kappaB transcriptional activation and tumor necrosis factor alpha production through RelA phosphorylation mediated by mitogen- and stressactivated protein kinase 1 in response to Borrelia burgdorferi antigens. Infect Immun 2007; 75: 270-7.

[24] Saccani S, Pantano S, Natoli G. p38-Dependent marking of inflammatory genes for increased NF-kappa B recruitment. Nat Immunol 2002; 3: 69-75.

[25] Beck IM, Vanden Berghe W, Vermeulen L, et al. Altered subcellular distribution of MSK1 induced by glucocorticoids contributes to NFkappaB inhibition. EMBO J 2008; 27: 1682-93.

[26] Vermeulen L, De Wilde G, Damme PV, Vanden BW, Haegeman G. Transcriptional activation of the NF-kappaB p65 subunit by mitogenand stress-activated protein kinase-1 (MSK1). EMBO J 2003; 22: 1313-24.

[27] Hao S, Baltimore D. The stability of mRNA influences the temporal order of the induction of genes encoding inflammatory molecules. Nat Immunol 2009; 10: 281-8.

[28] Raghavan A, Bohjanen PR. Microarray-based analyses of mRNA decay in the regulation of mammalian gene expression. Brief Funct Genomic Proteomic 2004; 3: 112-24.

[29] Cheadle C, Fan J, Cho-Chung YS, et al. Stability regulation of mRNA and the control of gene expression. Ann N Y Acad Sci 2005; 1058: 196-204.

[30] Clark A, Dean J, Tudor C, Saklatvala J. Post-transcriptional gene regulation by MAP kinases via AU-rich elements. Front Biosci 2009; 14: 847-71

[31] Garneau NL, Wilusz J, Wilusz CJ. The highways and byways of mRNA decay. Nat Rev Mol Cell Biol 2007; 8: 113-26.

[32] Lykke-Andersen J, Wagner E. Recruitment and activation of mRNA decay enzymes by two ARE-mediated decay activation domains in the proteins TTP and BRF-1. Genes Dev 2005; 19: 351-61.

[33] Marchese FP, Aubareda A, Tudor C, Saklatvala J, Clark AR, Dean JL. MAPKAP kinase 2 blocks tristetraprolin-directed mRNA decay by inhibiting CAF1 deadenylase recruitment. J Biol Chem 2010; 285 : 27590-600.

[34] Hau HH, Walsh RJ, Ogilvie RL, Williams DA, Reilly CS, Bohjanen PR. Tristetraprolin recruits functional mRNA decay complexes to ARE sequences. J Cell Biochem 2006; 100(6): 1477-92.

[35] Lai WS, Kennington EA, Blackshear PJ. Tristetraprolin and its family members can promote the cell-free deadenylation of AU-rich element-containing mRNAs by poly(A) ribonuclease. Mol Cell Biol 2003; 23: 3798-812.

[36] Clark AR, Dean JL, Saklatvala J. Post-transcriptional regulation of gene expression by mitogen-activated protein kinase p38. FEBS Lett 2003; 546: 37-44.

[37] Dean JL, Sully G, Clark AR, Saklatvala J. The involvement of AUrich element-binding proteins in $\mathrm{p} 38$ mitogen-activated protein kinase pathway-mediated mRNA stabilisation. Cell Signal 2004; 16: 111321. 
[38] Ronkina N, Menon MB, Schwermann J, et al. MAPKAP kinases MK2 and MK3 in inflammation: Complex regulation of TNF biosynthesis via expression and phosphorylation of tristetraprolin. Biochem Pharmacol 2010; 80(12): 1915-20.

[39] Sandler H, Stoecklin G. Control of mRNA decay by phosphorylation of tristetraprolin. Biochem Soc Trans 2008; 36: 491-6.

[40] Chrestensen CA, Schroeder MJ, Shabanowitz J, et al. MAPKAP kinase 2 phosphorylates tristetraprolin on in vivo sites including Ser178, a site required for 14-3-3 binding. J Biol Chem 2004; 279 : 10176-84.

[41] Mahtani KR, Brook M, Dean JL, Sully G, Saklatvala J, Clark AR. Mitogen-activated protein kinase p38 controls the expression and posttranslational modification of tristetraprolin, a regulator of tumor necrosis factor alpha mRNA stability. Mol Cell Biol 2001; 21: 64619.

[42] Ronkina N, Kotlyarov A, Dittrich-Breiholz O, et al. The mitogenactivated protein kinase (MAPK)-activated protein kinases MK2 and MK3 cooperate in stimulation of tumor necrosis factor biosynthesis and stabilization of p38 MAPK. Mol Cell Biol 2007; 27: 170-81.

[43] Brook M, Sully G, Clark AR, Saklatvala J. Regulation of tumour necrosis factor alpha mRNA stability by the mitogen-activated protein kinase p38 signalling cascade. FEBS Lett 2000; 483: 57-61.

[44] Dean JL, Brook M, Clark AR, Saklatvala J. p38 mitogen-activated protein kinase regulates cyclooxygenase- 2 mRNA stability and transcription in lipopolysaccharide-treated human monocytes. J Biol Chem 1999; 274: 264-9.

[45] Dean JL, Sarsfield SJ, Tsounakou E, Saklatvala J. p38 Mitogenactivated protein kinase stabilizes mRNAs that contain cyclooxygenase- 2 and tumor necrosis factor AU-rich elements by inhibiting deadenylation. J Biol Chem 2003; 278: 39470-6.

[46] Lasa M, Mahtani KR, Finch A, Brewer G, Saklatvala J, Clark AR. Regulation of cyclooxygenase 2 mRNA stability by the mitogenactivated protein kinase p38 signaling cascade. Mol Cell Biol 2000; 20: 4265-74

[47] Miyazawa K, Mori A, Miyata H, Akahane M, Ajisawa Y, Okudaira H. Regulation of interleukin-1beta-induced interleukin-6 gene expression in human fibroblast-like synoviocytes by p38 mitogenactivated protein kinase. J Biol Chem1998; 273: 24832-8.

[48] Tudor C, Marchese FP, Hitti E, et al. The p38 MAPK pathway inhibits tristetraprolin-directed decay of interleukin-10 and proinflammatory mediator mRNAs in murine macrophages. FEBS Lett 2009; 583: 1933-8.

[49] Keffer J, Probert L, Cazlaris H, et al. Transgenic mice expressing human tumour necrosis factor: a predictive genetic model of arthritis. EMBO J 1991; 10: 4025-31.

[50] Butler DM, Malfait AM, Mason LJ, et al. DBA/1 mice expressing the human TNF-alpha transgene develop a severe, erosive arthritis: characterization of the cytokine cascade and cellular composition. J Immunol 1997; 159: 2867-76.

[51] Kontoyiannis D, Pasparakis M, Pizarro TT, Cominelli F, Kollias G. Impaired on/off regulation of TNF biosynthesis in mice lacking TNF AU-rich elements: implications for joint and gut-associated immunopathologies. Immunity 1999; 10: 387-98.

[52] Taylor GA, Carballo E, Lee DM, et al. A pathogenetic role for TNF alpha in the syndrome of cachexia, arthritis, and autoimmunity resulting from tristetraprolin (TTP) deficiency. Immunity 1996; 4: 445-54.

[53] Carballo E, Gilkeson GS, Blackshear PJ. Bone marrow transplantation reproduces the tristetraprolin-deficiency syndrome in recombination activating gene-2 (-/-) mice. Evidence that monocyte/macrophage progenitors may be responsible for TNFalpha overproduction. J Clin Invest 1997; 100: 986-95.

[54] Carballo E, Lai WS, Blackshear PJ. Feedback inhibition of macrophage tumor necrosis factor-alpha production by tristetraprolin. Science 1998; 281: 1001-5.

[55] Carrick DM, Lai WS, Blackshear PJ. The tandem CCCH zinc finger protein tristetraprolin and its relevance to cytokine mRNA turnover and arthritis. Arthritis Res Ther 2004; 6: 248-64.

[56] Owens DM, Keyse SM. Differential regulation of MAP kinase signalling by dual-specificity protein phosphatases. Oncogene 2007; 26: 3203-13

[57] Dickinson RJ, Keyse SM. Diverse physiological functions for dualspecificity MAP kinase phosphatases. J Cell Sci 2006; 119: 4607-15.

[58] Abraham SM, Clark AR. Dual-specificity phosphatase 1: a critical regulator of innate immune responses. Biochem Soc Trans 2006; 34 : 1018-23.
[59] Li L, Chen SF, Liu Y. MAP kinase phosphatase-1, a critical negative regulator of the innate immune response. Int J Clin Exp Med 2009; 2: 48-67.

[60] Wang X, Liu Y. Regulation of innate immune response by MAP kinase phosphatase-1. Cell Signal 2007; 19: 1372-82.

[61] Salojin KV, Owusu IB, Millerchip KA, Potter M, Platt KA, Oravecz T. Essential role of MAPK phosphatase-1 in the negative control of innate immune responses. J Immunol 2006; 176: 1899-907.

[62] Bhalla US, Ram PT, Iyengar R. MAP kinase phosphatase as a locus of flexibility in a mitogen-activated protein kinase signaling network. Science 2002; 297: 1018-23.

[63] Hammer M, Mages J, Dietrich H, et al. Control of dual-specificity phosphatase-1 expression in activated macrophages by IL-10. Eur J Immunol 2005; 35: 2991-3001.

[64] Zhao Q, Wang X, Nelin LD, et al. MAP kinase phosphatase 1 controls innate immune responses and suppresses endotoxic shock. J Exp Med 2006; 203: 131-40.

[65] Barnes PJ. Corticosteroids: the drugs to beat. Eur J Pharmacol 2006; 533: 2-14.

[66] Hillier SG. Diamonds are forever: the cortisone legacy. J Endocrinol 2007; 195: 1-6.

[67] Kirwan J, Power L. Glucocorticoids: action and new therapeutic insights in rheumatoid arthritis. Curr Opin Rheumatol 2007; 19: 2337.

[68] Pisu M, James N, Sampsel S, Saag KG. The cost of glucocorticoidassociated adverse events in rheumatoid arthritis. Rheumatology 2005; 44: 781-8.

[69] Schacke H, Docke WD, Asadullah K. Mechanisms involved in the side effects of glucocorticoids. Pharmacol Ther 2002; 96: 23-43.

[70] Clark AR. MAP kinase phosphatase 1: a novel mediator of biological effects of glucocorticoids? J Endocrinol 2003; 178: 5-12.

[71] Clark AR. Anti-inflammatory functions of glucocorticoid-induced genes. Mol Cell Endocrinol 2007; 275: 79-97.

[72] Clark AR, Martins JR, Tchen CR. Role of dual specificity phosphatases in biological responses to glucocorticoids. J Biol Chem 2008; 283: 25765-9.

[73] Abraham SM, Lawrence T, Kleiman A, et al. Antiinflammatory effects of dexamethasone are partly dependent on induction of dual specificity phosphatase 1. J Exp Med 2006; 203: 1883-9.

[74] Wang X, Nelin LD, Kuhlman JR, Meng X, Welty SE, Liu Y. The role of MAP kinase phosphatase-1 in the protective mechanism of dexamethasone against endotoxemia. Life Sci 2008; 83: 671-80.

[75] Bantel H, Schmitz ML, Raible A, Gregor M, Schulze-Osthoff K. Critical role of NF-kappaB and stress-activated protein kinases in steroid unresponsiveness. FASEB J 2002; 16: 1832-4.

[76] Bhavsar P, Hew M, Khorasani N, et al. Relative corticosteroid insensitivity of alveolar macrophages in severe asthma compared with non-severe asthma. Thorax 2008; 63: 784-90.

[77] Loke TK, Mallett KH, Ratoff J, et al. Systemic glucocorticoid reduces bronchial mucosal activation of activator protein 1 components in glucocorticoid-sensitive but not glucocorticoidresistant asthmatic patients. J Allergy Clin Immunol 2006; 118: 36875.

[78] Sousa AR, Lane $\mathrm{SJ}$, Soh C, Lee $\mathrm{TH}$. In vivo resistance to corticosteroids in bronchial asthma is associated with enhanced phosyphorylation of JUN N-terminal kinase and failure of prednisolone to inhibit JUN N-terminal kinase phosphorylation. J Allergy Clin Immunol 1999; 104: 565-74.

[79] Flaster H, Bernhagen J, Calandra T, Bucala R. The macrophage migration inhibitory factor-glucocorticoid dyad: regulation of inflammation and immunity. Mol Endocrinol 2007; 21: 1267-80.

[80] Santos LL, Morand EF. The role of macrophage migration inhibitory factor in the inflammatory immune response and rheumatoid arthritis. Wien Med Wochenschr 2006; 156: 11-8.

[81] Morand EF, Leech M, Bernhagen J. MIF: a new cytokine link between rheumatoid arthritis and atherosclerosis. Nat Rev Drug Discov 2006; 5: 399-410.

[82] Ishiguro Y, Ohkawara T, Sakuraba H, et al. Macrophage migration inhibitory factor has a proinflammatory activity via the p38 pathway in glucocorticoid-resistant ulcerative colitis. Clin Immunol 2006; 120(3): 335-41.

[83] Aeberli D, Yang Y, Mansell A, Santos L, Leech M, Morand EF. Endogenous macrophage migration inhibitory factor modulates glucocorticoid sensitivity in macrophages via effects on MAP kinase phosphatase-1 and p38 MAP kinase. FEBS Lett. 2006; 580: 974-81. 
[84] Roger T, Chanson AL, Knaup-Reymond M, Calandra T. Macrophage migration inhibitory factor promotes innate immune responses by suppressing glucocorticoid-induced expression of mitogen-activated protein kinase phosphatase-1. Eur J Immunol 2005; 35: 3405-13.

[85] Ralph JA, Ahmed AU, Santos LL, et al. Identification of NURR1 as a Mediator of MIF Signaling During Chronic Arthritis. Effects on Glucocorticoid-Induced MKP1. Am J Pathol 2010; 177(5):2366-78.

[86] Staples CJ, Owens DM, Maier JV, Cato AC, Keyse SM. Crosstalk between the p38 \{alpha\} and JNK MAP kinase pathways mediated by MAP kinase phosphatase-1 determines cellular sensitivity to UV radiation. J Biol Chem $2010 ; 285(34): 25928-40$.

[87] Ananieva O, Darragh J, Johansen C, et al. The kinases MSK1 and MSK2 act as negative regulators of Toll-like receptor signaling. Nat Immunol 2008; 9: 1028-36.

[88] Breitwieser W, Lyons S, Flenniken AM, et al. Feedback regulation of p38 activity via ATF2 is essential for survival of embryonic liver cells. Genes Dev 2007; 21: 2069-82.

[89] Cho IJ, Woo NR, Shin IC, Kim SG. H89, an inhibitor of PKA and MSK, inhibits cyclic-AMP response element binding proteinmediated MAPK phosphatase-1 induction by lipopolysaccharide. Inflamm Res 2009; 58: 863-72.

[90] Kim C, Sano Y, Todorova K, et al. The kinase p38 alpha serves cell type-specific inflammatory functions in skin injury and coordinates pro- and anti-inflammatory gene expression. Nat Immunol 2008; 9: 1019-27.

[91] Wong HR, Dunsmore KE, Page K, Shanley TP. Heat shock-mediated regulation of MKP-1. Am J Physiol Cell Physiol 2005; 289(5):C1152-8

[92] Emmons J, Townley-Tilson WH, Deleault KM, et al. Identification of TTP mRNA targets in human dendritic cells reveals TTP as a critical regulator of dendritic cell maturation. RNA 2008; 14: 888902.

[93] Lin NY, Lin CT, Chang CJ. Modulation of immediate early gene expression by tristetraprolin in the differentiation of 3T3-L1 cells. Biochem Biophys Res Commun 2008; 365: 69-74.

[94] Bros M, Wiechmann N, Besche V, et al. The RNA binding protein tristetraprolin influences the activation state of murine dendritic cells. Mol Immunol. 2010; 47: 1161-70.

[95] Hu JH, Chen T, Zhuang ZH, et al. Feedback control of MKP-1 expression by p38. Cell Signal 2007; 19: 393-400.

[96] Hutter D, Chen P, Barnes J, Liu Y. Catalytic activation of mitogenactivated protein (MAP) kinase phosphatase-1 by binding to p38 MAP kinase: critical role of the p38 C-terminal domain in its negative regulation. Biochem J 2000; 352: 155-63.

[97] Brook M, Tchen CR, Santalucia T, et al. Posttranslational regulation of tristetraprolin subcellular localization and protein stability by $\mathrm{p} 38$ mitogen-activated protein kinase and extracellular signal-regulated kinase pathways. Mol Cell Biol 2006; 26: 2408-18.

[98] Hitti E, Iakovleva T, Brook M, et al. Mitogen-activated protein kinase-activated protein kinase 2 regulates tumor necrosis factor mRNA stability and translation mainly by altering tristetraprolin expression, stability, and binding to adenine/uridine-rich element. Mol Cell Biol 2006; 26: 2399-407.

[99] Tchen CR, Brook M, Saklatvala J, Clark AR. The stability of tristetraprolin mRNA is regulated by mitogen-activated protein kinase p38 and by tristetraprolin itself. J Biol Chem 2004; 279: 32393-400.

[100] Sun L, Stoecklin G, Van Way S, et al. Tristetraprolin (TTP)-14-3-3 complex formation protects TTP from dephosphorylation by protein phosphatase $2 \mathrm{a}$ and stabilizes tumor necrosis factor-alpha mRNA. J Biol Chem 2007; 282: 3766-77.

[101] Williams LM, Ricchetti G, Sarma U, Smallie T, Foxwell BM. Interleukin-10 suppression of myeloid cell activation--a continuing puzzle. Immunology 2004; 113: 281-92.

[102] Murray PJ. Understanding and exploiting the endogenous interleukin10/STAT3-mediated anti-inflammatory response. Curr Opin Pharmacol 2006; 6: 379-86.

[103] Saraiva M, O'Garra A. The regulation of IL-10 production by immune cells. Nat Rev Immunol 2010; 10: 170-81.

[104] Walmsley M, Katsikis PD, Abney E, et al. Interleukin-10 inhibition of the progression of established collagen-induced arthritis. Arthritis Rheum 1996; 39: 495-503.

[105] Finnegan A, Kaplan CD, Cao Y, Eibel H, Glant TT, Zhang J. Collagen-induced arthritis is exacerbated in IL-10-deficient mice. Arthritis Res Ther 2003; 5: R18-24.
[106] Ma W, Lim W, Gee K, et al. The p38 mitogen-activated kinase pathway regulates the human interleukin-10 promoter via the activation of Sp1 transcription factor in lipopolysaccharide-stimulated human macrophages. J Biol Chem 2001; 276: 13664-74.

[107] Pilette C, Detry B, Guisset A, Gabriels J, Sibille Y. Induction of interleukin-10 expression through Fcalpha receptor in human monocytes and monocyte-derived dendritic cells: role of p38 MAPKinase. Immunol Cell Biol 2010; 88: 486-93.

[108] Stoecklin G, Tenenbaum SA, Mayo T, et al. Genome-wide analysis identifies interleukin-10 mRNA as target of tristetraprolin. J Biol Chem 2008.

[109] Cheung PC, Campbell DG, Nebreda AR, Cohen P. Feedback control of the protein kinase TAK1 by SAPK2a/p38alpha. EMBO J 2003; 22: 5793-805.

[110] Mendoza H, Campbell DG, Burness K, et al. Roles for TAB1 in regulating the IL-1-dependent phosphorylation of the TAB3 regulatory subunit and activity of the TAK1 complex. Biochem J 2008; 409: 711-22.

[111] Shin MS, Shinghirunnusorn P, Sugishima Y, et al. Cross interference with TNF-alpha-induced TAK1 activation via EGFR-mediated p38 phosphorylation of TAK1-binding protein 1. Biochim Biophys Acta 2009; 1793: 1156-64

[112] Thiefes A, Wolf A, Doerrie A, et al. The Yersinia enterocolitica effector YopP inhibits host cell signalling by inactivating the protein kinase TAK1 in the IL-1 signalling pathway. EMBO Rep 2006; 7 : 838-44.

[113] Muniyappa H, Das KC. Activation of c-Jun N-terminal kinase (JNK) by widely used specific p38 MAPK inhibitors SB202190 and SB203580: a MLK-3-MKK7-dependent mechanism. Cell Signal 2008; 20: 675-83.

[114] Ehlting C, Lai WS, Schaper F, et al. Regulation of suppressor of cytokine signaling 3 (SOCS3) mRNA stability by TNF-alpha involves activation of the MKK6/p38MAPK/MK2 cascade. J Immunol 2007; 178: 2813-26.

[115] Qin H, Roberts KL, Niyongere SA, Cong Y, Elson CO, Benveniste EN. Molecular mechanism of lipopolysaccharide-induced SOCS-3 gene expression in macrophages and microglia. J Immunol 2007; 179: 5966-76.

[116] Kiu H, Hilton DJ, Nicola NA, et al. Mechanism of crosstalk inhibition of IL-6 signaling in response to LPS and TNFalpha. Growth Factors 2007; 25: 319-28.

[117] Lee JC, Laydon JT, McDonnell PC, et al. A protein kinase involved in the regulation of inflammatory cytokine biosynthesis. Nature 1994; 372: 739-46.

[118] Sweeney SE. The as-yet unfulfilled promise of p38 MAPK inhibitors. Nat Rev Rheumatol 2009; 5: 475-7.

[119] Schieven GL. The p38alpha kinase plays a central role in inflammation. Curr Top Med Chem 2009; 9: 1038-48.

[120] Cohen P. Targeting protein kinases for the development of antiinflammatory drugs. Curr Opin Cell Biol 2009; 21: 317-24.

[121] Stanczyk J, Ospelt C, Gay S. Is there a future for small molecule drugs in the treatment of rheumatic diseases? Curr Opin Rheumatol 2008; 20: 257-62

[122] Beardmore VA, Hinton HJ, Eftychi C, et al. Generation and characterization of p38beta (MAPK11) gene-targeted mice. Mol Cell Biol 2005; 25: 10454-64

[123] Bohm C, Hayer S, Kilian A, et al. The alpha-isoform of p38 MAPK specifically regulates arthritic bone loss. J Immunol 2009; 183: 593847.

[124] Hegen M, Gaestel M, Nickerson-Nutter CL, Lin LL, Telliez JB. MAPKAP kinase 2-deficient mice are resistant to collagen-induced arthritis. J Immunol 2006; 177: 1913-7.

[125] Inoue T, Boyle DL, Corr M, et al. Mitogen-activated protein kinase kinase 3 is a pivotal pathway regulating p38 activation in inflammatory arthritis. Proc Natl Acad Sci U S A 2006; 103: 5484-9.

[126] Yoshizawa T, Hammaker D, Boyle DL, et al. Role of MAPK kinase 6 in arthritis: distinct mechanism of action in inflammation and cytokine expression. J Immunol 2009; 183: 1360-7.

[127] Hammaker DR, Boyle DL, Chabaud-Riou M, Firestein GS Regulation of c-Jun N-terminal kinase by MEKK-2 and mitogenactivated protein kinase kinase kinases in rheumatoid arthritis. J Immunol 2004; 172: 1612-8.

[128] Gortz B, Hayer S, Tuerck B, Zwerina J, Smolen JS, Schett G. Tumour necrosis factor activates the mitogen-activated protein kinases p38alpha and ERK in the synovial membrane in vivo. Arthritis Res Ther 2005; 7: R1140-7. 
[129] Korb A, Tohidast-Akrad M, Cetin E, Axmann R, Smolen J, Schett G. Differential tissue expression and activation of p38 MAPK alpha, beta, gamma, and delta isoforms in rheumatoid arthritis. Arthritis Rheum 2006; 54: 2745-56.

[130] Zwerina J, Hayer S, Redlich K, et al. Activation of p38 MAPK is a key step in tumor necrosis factor-mediated inflammatory bone destruction. Arthritis Rheum 2006; 54: 463-72.

[131] Schett G, Tohidast-Akrad M, Smolen JS, et al. Activation, differential localization, and regulation of the stress-activated protein kinases, extracellular signal-regulated kinase, c-JUN N-terminal kinase, and p38 mitogen-activated protein kinase, in synovial tissue and cells in rheumatoid arthritis. Arthritis Rheum 2000; 43: 2501-12.

[132] Schett G, Zwerina J, Firestein G. The p38 mitogen-activated protein kinase (MAPK) pathway in rheumatoid arthritis. Ann Rheum Dis 2008; 67: 909-16.

[133] Hayer S, Steiner G, Gortz B, et al. CD44 is a determinant of inflammatory bone loss. J Exp Med 2005; 201: 903-14.

[134] Chabaud-Riou M, Firestein GS. Expression and activation of mitogen-activated protein kinase kinases-3 and -6 in rheumatoid arthritis. Am J Pathol 2004; 164: 177-84.

[135] Zaidi M. Skeletal remodeling in health and disease. Nat Med 2007; 13: 791-801

[136] Leibbrandt A, Penninger JM. RANKL/RANK as key factors for osteoclast development and bone loss in arthropathies. Adv Exp Med Biol 2009; 649: 100-13.

[137] Huang H, Chang EJ, Ryu J, Lee ZH, Lee Y, Kim HH. Induction of cFos and NFATc1 during RANKL-stimulated osteoclast differentiation is mediated by the p38 signaling pathway. Biochem Biophys Res Commun 2006; 351: 99-105.

[138] Huang H, Ryu J, Ha J, et al. Osteoclast differentiation requires TAK1 and MKK6 for NFATc1 induction and NF-kappaB transactivation by RANKL. Cell Death Differ 2006; 13: 1879-91.

[139] Mansky KC, Sankar U, Han J, Ostrowski MC. Microphthalmia transcription factor is a target of the p38 MAPK pathway in response to receptor activator of NF-kappa B ligand signaling. J Biol Chem 2002; 277: 11077-83.

[140] Matsumoto M, Kogawa M, Wada S, et al. Essential role of p38 mitogen-activated protein kinase in cathepsin $\mathrm{K}$ gene expression during osteoclastogenesis through association of NFATc1 and PU.1. J Biol Chem 2004; 279: 45969-79.

[141] Saha B, Singh SK, Sarkar C, et al. Activation of the Mitf promoter by lipid-stimulated activation of p38-stress signalling to CREB. Pigment Cell Res 2006; 19: 595-605.

[142] Sharma SM, Bronisz A, Hu R, et al. MITF and PU.1 recruit p38 MAPK and NFATc1 to target genes during osteoclast differentiation. J Biol Chem 2007; 282: 15921-9.

[143] Takayanagi H, Kim S, Koga T, et al. Induction and activation of the transcription factor NFATc1 (NFAT2) integrate RANKL signaling in terminal differentiation of osteoclasts. Dev Cell 2002; 3: 889-901.

[144] Li X, Udagawa N, Takami M, Sato N, Kobayashi Y, Takahashi N. p38 Mitogen-activated protein kinase is crucially involved in osteoclast differentiation but not in cytokine production, phagocytosis, or dendritic cell differentiation of bone marrow macrophages. Endocrinology 2003; 144: 4999-5005.

[145] Ridley SH, Sarsfield SJ, Lee JC, et al. Actions of IL-1 are selectively controlled by $\mathrm{p} 38$ mitogen-activated protein kinase: regulation of prostaglandin $\mathrm{H}$ synthase-2, metalloproteinases, and IL-6 at different levels. J Immunol 1997; 158: 3165-73.

[146] Ahmad R, Sylvester J, Zafarullah M. MyD88, IRAK1 and TRAF6 knockdown in human chondrocytes inhibits interleukin-1-induced matrix metalloproteinase-13 gene expression and promoter activity by impairing MAP kinase activation. Cell Signal 2007; 19: 2549-57.

[147] Mengshol JA, Vincenti MP, Brinckerhoff CE. IL-1 induces collagenase-3 (MMP-13) promoter activity in stably transfected chondrocytic cells: requirement for Runx-2 and activation by $\mathrm{p} 38$ MAPK and JNK pathways. Nucleic Acids Res 2001; 29: 4361-72.
[148] Pei Y, Harvey A, Yu XP, Chandrasekhar S, Thirunavukkarasu K. Differential regulation of cytokine-induced MMP-1 and MMP-13 expression by $\mathrm{p} 38$ kinase inhibitors in human chondrosarcoma cells: potential role of Runx 2 in mediating p38 effects. Osteoarthr Cartil 2006; 14: 749-58.

[149] Hammaker D, Firestein GS. "Go upstream, young man": lessons learned from the p38 saga. Ann Rheum Dis 2010; 69 Suppl 1: i77-82.

[150] Delaney JR, Mlodzik M. TGF-beta activated kinase-1: new insights into the diverse roles of TAK1 in development and immunity. Cell Cycle 2006; 5: 2852-5.

[151] Gaestel M, Mengel A, Bothe U, Asadullah K. Protein kinases as small molecule inhibitor targets in inflammation. Curr Med Chem 2007; 14: 2214-34.

[152] Sato S, Sanjo H, Takeda K, et al. Essential function for the kinase TAK1 in innate and adaptive immune responses. Nat Immunol 2005; 6: 1087-95.

[153] Sato S, Sanjo H, Tsujimura T, et al. TAK1 is indispensable for development of $\mathrm{T}$ cells and prevention of colitis by the generation of regulatory T cells. Int Immunol 2006; 18: 1405-11.

[154] Cohen P, Tcherpakov M. Will the ubiquitin system furnish as many drug targets as protein kinases? Cell 2010; 143: 686-93.

[155] Duraisamy S, Bajpai M, Bughani U, Dastidar SG, Ray A, Chopra P. MK2: a novel molecular target for anti-inflammatory therapy. Expert Opin Ther Targets 2008; 12:921-36.

[156] Mourey RJ, Burnette BL, Brustkern SJ, et al. A benzothiophene inhibitor of mitogen-activated protein kinase-activated protein kinase 2 inhibits tumor necrosis factor alpha production and has oral antiinflammatory efficacy in acute and chronic models of inflammation. J Pharmacol Exp Ther 2010; 333: 797-807.

[157] Kontoyiannis D, Boulougouris G, Manoloukos M, et al. Genetic dissection of the cellular pathways and signaling mechanisms in modeled tumor necrosis factor-induced Crohn's-like inflammatory bowel disease. J Exp Med 2002; 196: 1563-74.

[158] Schottelius AJ, Zugel U, Docke WD, et al. The role of mitogenactivated protein kinase-activated protein kinase 2 in the p38/TNFalpha pathway of systemic and cutaneous inflammation. J Invest Dermatol 2010; 130: 481-91.

[159] Lehner MD, Schwoebel F, Kotlyarov A, Leist M, Gaestel M, Hartung T. Mitogen-activated protein kinase-activated protein kinase 2deficient mice show increased susceptibility to Listeria monocytogenes infection. J Immunol 2002; 168: 4667-73.

[160] Damjanov N, Kauffman RS, Spencer-Green GT. Efficacy, pharmacodynamics, and safety of VX-702, a novel p38 MAPK inhibitor, in rheumatoid arthritis: Results of two randomized, doubleblind, placebo-controlled clinical studies. Arthritis Rheum 2009; 60: $1232-41$.

[161] Genovese MC. Inhibition of p38: has the fat lady sung? Arthritis Rheum 2009; 60: 317-20.

[162] Keren A, Tamir Y, Bengal E. The p38 MAPK signaling pathway: a major regulator of skeletal muscle development. Mol Cell Endocrinol 2006; 252: 224-30.

[163] Tamura K, Sudo T, Senftleben U, Dadak AM, Johnson R, Karin M. Requirement for $\mathrm{p} 38 \mathrm{a}$ in erythropoietin expression: a role for stress kinases in erythropoiesis. Cell 2000; 102: 221-31.

[164] Greenblatt MG, Shim JH, Zou W, et al. The p38 MAPK pathway is essential for skeletogenesis and bone homeostasis in mice. J Clin Invest 2010; 120: 2457-73.

[165] Clark AR, Dean JL, Saklatvala J. The p38 MAPK pathway mediates both antiinflammatory and proinflammatory processes: comment on the article by Damjanov and the editorial by Genovese. Arthritis Rheum 2010; 60: 3513-4.

[166] Xia ZP, Sun L, Chen X, et al. Direct activation of protein kinases by unanchored polyubiquitin chains. Nature 2009; 461: 114-9.

[167] Fan Y, Yu Y, Shi Y, et al. Lysine 63-linked polyubiquitination of TAK1 at lysine 158 is required for tumor necrosis factor alpha- and interleukin-1beta-induced IKK/NF-kappaB and JNK/AP-1 activation. J Biol Chem 2010; 285: 5347-60. 